\title{
Middle East Respiratory Syndrome Virus Pathogenesis
}

\author{
Sunit K. Singh, $\mathrm{PhD}^{1}$ \\ ${ }^{1}$ Molecular Biology Unit, Institute of Medical Sciences, Banaras Hindu \\ University (BHU), Varanasi, Uttar Pradesh, India \\ Semin Respir Crit Care Med 2016;37:572-577.

\begin{abstract}
Address for correspondence Sunit K. Singh, PhD, Molecular Biology Unit, Institute of Medical Sciences, Banaras Hindu University (BHU), Varanasi 221005, Uttar Pradesh, India (e-mail: sunitsingh2000@gmail.com).
\end{abstract}

\begin{abstract}
Keywords

- coronavirus

- SARS-CoV

- MERS-CoV

Coronaviruses (CoVs) are enveloped RNA viruses that infect birds, mammals, and humans. Infections caused by human coronaviruses (hCoVs) are mostly associated with the respiratory, enteric, and nervous systems. The hCoVs only occasionally induce lower respiratory tract disease, including bronchitis, bronchiolitis, and pneumonia. In 2002 to 2003, a global outbreak of severe acute respiratory syndrome (SARS) was the seminal detection of a novel CoV (SARS-CoV). A decade later (June 2012), another novel CoV was implicated as the cause of Middle East respiratory syndrome (MERS) in Saudi Arabia. Although bats might serve as a reservoir of MERS-CoV, it is unlikely that they are the direct source for most human cases. Severe lines of evidence suggest that dromedary camels have been the major cause of transmission to humans. The emergence of MERS-CoV has triggered serious concerns about the potential for a widespread outbreak. All MERS cases were linked directly or indirectly to the Middle East region including Saudi Arabia, Jordan, Qatar, Oman, Kuwait, and UAE. MERS cases have also been reported in the later phases in the United Kingdom, France, Germany, Italy, Spain, and Tunisia. Most of these MERS cases were linked with the Middle East. The high mortality rates in family-based and hospitalbased outbreaks were reported among patients with comorbidities such as diabetes and renal failure. MERS-CoV causes an acute, highly lethal pneumonia and renal dysfunction. The major complications reported in fatal cases are hyperkalemia with associated ventricular tachycardia, disseminated intravascular coagulation, pericarditis, and multiorgan failure. The case-fatality rate seems to be higher for MERS-CoV (around 30\%) than for SARS-CoV (9.6\%). The combination regimen of type 1 interferon + lopinavir/ritonavir is considered as the first-line therapy for MERS. Antiviral treatment is generally recommended for 10 to 14 days in patients with MERS-CoV infection. Convalescent plasma therapy has shown some efficacy among patients refractory to antiviral drugs if administered within 2 weeks of the onset of the disease.
\end{abstract}

Coronaviruses (CoVs) are enveloped, positive sense RNA viruses, infecting birds and mammals. CoVs belong to the family of Coronaviridae and the subfamily Coronavirinae. Infections caused by human coronaviruses (hCoVs) are mostly associated with the respiratory, enteric, and nervous systems. These are divided into four genera: $\alpha, \beta, \gamma$, and $\delta$. Among the hCoVs, the HKU1, NL63, 229E, and OC43 are endemic in the human population and responsible for mild, self-limiting upper respiratory tract infections. ${ }^{1,2}$ In addition, the hCoVs also induce lower respiratory tract disease, including bronchitis, bronchiolitis, and pneumonia. ${ }^{3-6}$ Severe acute respiratory syndrome coronavirus (SARS-CoV) and Middle East respiratory syndrome coronavirus (MERS-CoV) are genetically subgrouped into lineages $\mathrm{B}$ and $\mathrm{C}$, respectively.

The first case of MERS was reported in Jeddah, Saudi Arabia, in June 2012. The outbreak of MERS-CoV infections started a
Issue Theme Respiratory Viral Infections; Guest Editor: Sunit K. Singh, PhD
Copyright $\odot 2016$ by Thieme Medical Publishers, Inc., 333 Seventh Avenue, New York, NY 10001, USA. Tel: +1(212) 584-4662. 
decade after the outbreak of the SARS-CoV epidemic in 2002$2003{ }^{7,8}$ The inefficient spread between infected patients suggested the strong possibility of zoonotic transmission, but the exact source of infection is still not known in human population. The Tylonycteris and Pipistrellus bats have been recently reported as the reservoir of MERS-CoV. ${ }^{9}$ Although bats might serve as a reservoir of MERS-CoV, it is unlikely that they are the direct source for most of the human cases because human contacts with bats are not very common. The phylogenetic studies revealed the presence of CoV RNA sequences in the bat fecal samples in Europe, Africa, and Asia, including the Middle East. Some of the RNA sequences have been reported to be closely related to MERS-CoV sequences. ${ }^{10-14}$ The MERS-CoV spilled over in human population either from bats or through other animals as intermediate hosts. ${ }^{10}$ However, other evidences indicated the origin of MERS-CoV from dromedary camels. High levels of neutralizing antibodies, viral RNA, and infectious viruses have been reported in dromedary camels, suggesting a potential for camels to be the source for human transmission. ${ }^{15,16}$ The presence of MERS-CoV neutralizing antibodies in dromedary camels suggested either a past infection with MERS-CoV or a closely related virus in camels. ${ }^{17,18}$ Unpasteurized camel milk has also been suggested as a potential source because the virus has been detected in the camel milk., ${ }^{8,20}$ The World Health Organization (WHO), Saudi Arabia, and Qatar have issued recommendation for not consuming unpasteurized camel milk and to be cautious in cases of close association with dromedary camels. ${ }^{20}$ The full-genome sequencing data have shown the sequence similarity in the MERS-CoV isolated from a man and his camel in Saudi Arabia. Such sequence similarity indicated camels as a strong possible link in the cases of camelto-human transmission. ${ }^{21}$ The phylogenetic studies provided the evidence of interspecies jumps of CoVs. ${ }^{22,23}$ The emergence of MERS-CoV has triggered serious concerns about the potential for a widespread outbreak. All MERS cases were linked directly or indirectly to the Middle East region including Saudi Arabia, Jordan, Qatar, Oman, Kuwait, and UAE. ${ }^{11,24}$ The MERS cases have also been reported in the later phases in the United Kingdom, France, Germany, Italy, Spain, and Tunisia. ${ }^{25}$ Most of these MERS cases were linked with the Middle East. ${ }^{25}$ The high mortality rates in family-based and hospital-based outbreaks were reported among patients with comorbidities such as diabetes and renal failure. $24,26,27$

\section{Molecular Virology of MERS-CoV}

The MERS-CoV genome consists of 30,119 nucleotides and 11 open reading frames (ORFs). ${ }^{2,28}$ The single positive-stranded RNA genome has 5'-UTR (278 nucleotides) and 3'-UTR (300 nucleotides) ( - Fig. 1). The genes located at the $5^{\prime}$-UTR play an important role in viral replication, whereas the genes at the 3'-UTR encode accessory and structural proteins. ${ }^{13}$ The 5'-UTR has two overlapping ORFs (ORF1a and ORF1b), which gets translated to two polyproteins (polyprotein 1a [pp1a] and polyprotein $1 \mathrm{ab}$ [pp1ab]) (-Fig. 1). ${ }^{28}$ These polyproteins are cleaved into 16 functional nonstructural proteins (nsps) through proteolytic activity of two viral proteases called papain-like protease (PLpro) and 3C-like protease (3CLPro) after their self-cleavage from pp1ab ( - Fig. 1). ${ }^{2,25,29,30}$ PLpro and 3CLpro are located on nsp3 and ns5, respectively. ${ }^{31}$ Other nsps encoded by ORFs are nsp12 (for RNA-dependent RNA polymerase activity), nsp14 (for exoribonuclease activity), nsp15 (for exoribonuclease activity), and nsp16 (for methyl transferase activity) (-Fig. 1). 2,32,33 The nsp14 plays an important role in proofreading activity to monitor the rate of mutation. ${ }^{33}$ The other genes downstream to ORF1ab encode for structural proteins such as Spike (S), envelope $(\mathrm{E})$, membrane $(\mathrm{M})$, and nucleocapsid $(\mathrm{N})$ and accessory proteins. ${ }^{25}$ The accessory proteins might help the virus in immune evasion by interfering with the innate immune response. MERS-CoV has five accessory proteins and SARS-CoV has eight different accessory proteins. ${ }^{32}$ These differences might lead to the differences in the effects on induction and signaling of type 1 interferons (IFNs), ${ }^{32}$ which could explain the greater sensitivity of IFN to MERS-CoV than SARS-CoV. ${ }^{34,35}$ The viral RNA is encapsidated in the N protein and transported to the endoplasmic reticulum-Golgi intermediate compartment (ERGIC), the site of assembly. Viral RNA encapsidated in the $\mathrm{N}$ protein and then buds into vesicles lined with the S, M, and E proteins. ${ }^{32}$ The dipeptidyl-peptidase 4 (DPP4/CD26) was identified as the host-cell receptor for the entry of MERS-CoV. ${ }^{13,36}$ Both MERS-CoV and SARS-CoV bind to large ectopeptidases (DPP4 and ACE2, respectively) to invade the cells. ${ }^{36,37}$ The aminopeptidase N (APN) has been reported as entry receptors for several $\alpha-\mathrm{CoVs}^{38}$ All hCoV receptors reported so far are exopeptidases, although their proteolytic activity is not necessary for the virus to bind to the receptors, or for entering in the host cells. ${ }^{5,39-41}$ MERS-CoV can bind to the DPP4 of the several species, but the binding site of DPP4 is different in different species, explaining the variation in the susceptibility of MERS-CoV infections in various animals. ${ }^{42}$ The S glycoprotein located on the surface of the MERS$\mathrm{CoV}$ virion interacts with the receptor binding domain of DPP4 to enter in the host cells. ${ }^{2,36,43}$ The $\mathrm{S}$ protein consists of a globular S1 domain at the N-terminal region, an S2 domain with two heptad repeats (HR1 and HR2), and a transmembrane domain. ${ }^{3}$ Lower rate of mutation has been reported so far in the MERS-CoV during transmission in human populations in the recent outbreaks.

Both hACE2 and DPP4 have been reported to shed from cell surface. ${ }^{38,44}$ The loss of hACE2 results in more severe pulmonary disease. $^{45}$ The DPP4 has been reported as a neutrophil chemo repellent; therefore, the variations in DPP4 shedding during MERS-CoV infection could influence the composition of the immune infiltrate, and ultimately to the outcome of the infection. DPP4 has also been reported to be expressed on immune cells, including $\mathrm{T}$ cell lymphocytes, and required for optimal function of these cells. ${ }^{38}$ The events occurring immediately after MERS-CoV binding with the DPP4 receptor appear to be similar to other CoVs. Cleavage of the surface glycoprotein is one of the necessary steps, which exposes the fusion peptide and facilitates the fusion of virus-cell membrane, which results into the release of the nucleocapsid in the cell cytoplasm. Several host proteases, including cathepsin B and members of the transmembrane protease, serine 2 (TMPRSS) family, have been implicated in this process. $^{38,46}$ 


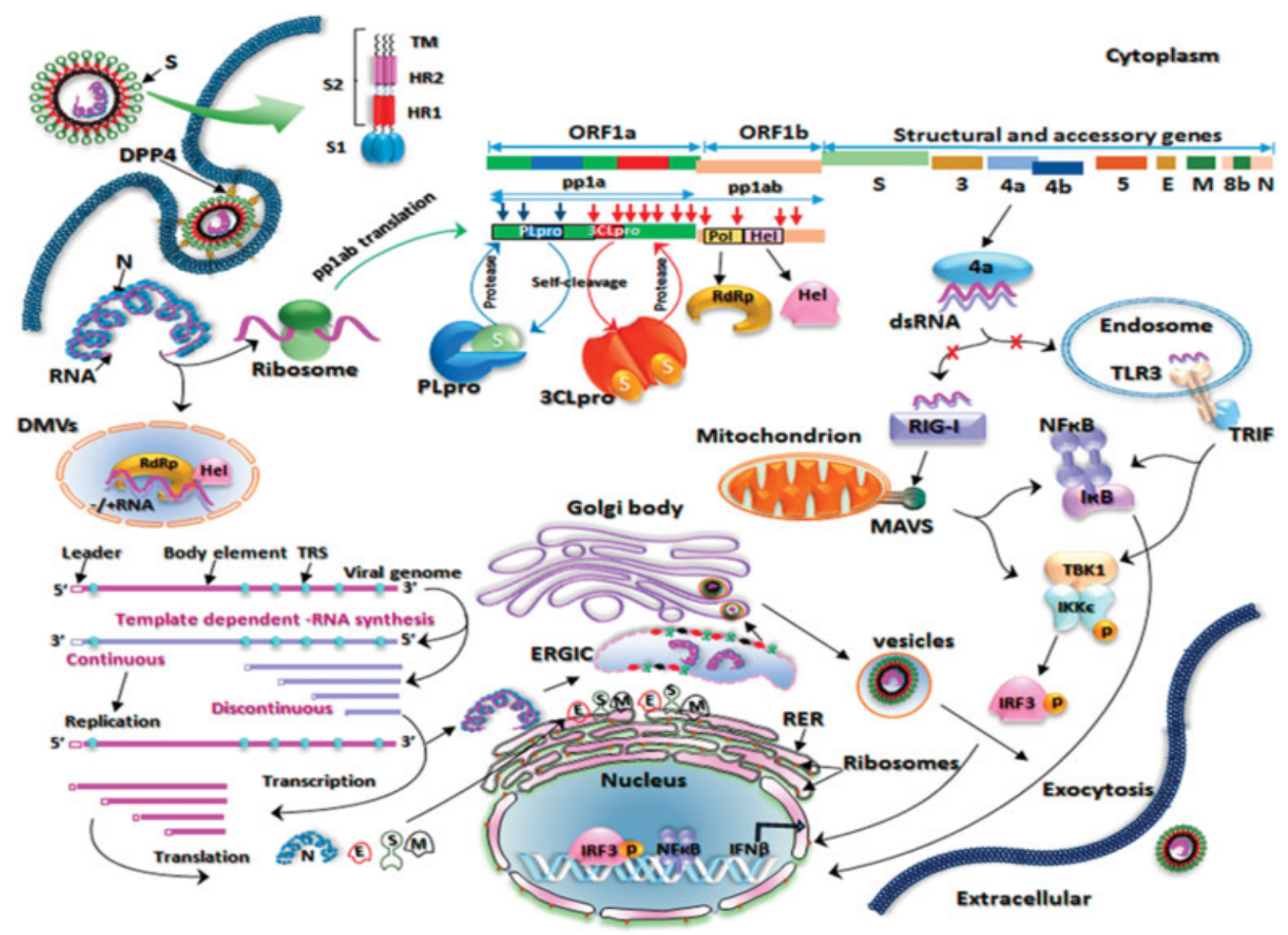

Fig. 1 Schematic of the replication cycle of Middle East respiratory syndrome coronavirus (MERS-CoV). MERS-CoV binds to dipeptidyl peptidase 4 (DPP4) on the host cell through its receptor-binding domain (RBD) in the S1 subunit of the spike (S) glycoprotein, which leads to virus-cell fusion and the release of genomic RNA into the cytoplasm. Initially open reading frame 1a (ORF-1a) and ORF-1b are translated into polyproteins, polyprotein 1a (pp1a) and pp1ab, respectively, which are cleaved by the virus-encoded proteases papain-like protease (PLpro) and 3C-like protease (3CLpro) into 16 mature nonstructural proteins (nsps). The proteins involved in replication and transcription are gathered into replicationtranscription complexes (RTCs) that associate with double-membrane vesicles (DMVs) derived from the endoplasmic reticulum (ER). The genomic RNA contains adenylate uridylate (AU)-rich sequences called transcription regulation sequences (TRSs). If the TRSs are recognized by RTCs, then RNA of subgenomic length for transcription will be generated, otherwise a full-length template RNA of genomic length for replication will be synthesized. The newly produced genomic RNAs are encapsidated in the nucleocapsid ( $N$ ) proteins in the cytoplasm and then transported to the ER-Golgi intermediate compartment (ERGIC) for further assembly. The $S$, membrane (M), and envelope (E) proteins are inserted into the membrane of the rough ER (RER), from where they are transported to the ERGIC to interact with the RNA-encapsidated N proteins and assemble into viral particles. The budded vesicles containing mature viral particles are then transported to the cell surface for release after maturation in the Golgi bodies. Double-stranded RNAs (dsRNAs) are partially generated during viral replication. The 4a competes with Toll-like receptor 3 (TLR3) and retinoic acid-inducible gene I product (RIG-I)-like helicases (RIG-I and melanoma differentiation-associated protein 5 [MDA5]) to bind to dsRNAs and evades the host immune response. (Adapted from Durai P, Batool M, Shah M, Choi S., Middle East respiratory syndrome coronavirus: transmission, virology and therapeutic targeting to aid in outbreak control. Exp Mol Med 2015;47:e181; doi:10.1038/emm.2015.76 under Creative Commons CC-BY license (Creative Commons Attribution 4.0 International License.) ${ }^{2}$

\section{Immunopathogenesis of MERS-CoV}

MERS-CoV causes an acute, highly lethal pneumonia and renal dysfunction. Renal dysfunctions take place either due to hypoxic damage or direct infection of the kidney. The entry receptor (DPP4) for MERS-CoV is expressed at high levels in the kidney. ${ }^{47}$ Neutrophil and macrophage infiltration and alveolar edema have been reported in infected lung tissues in the MERS animal models. ${ }^{32}$ The cell-line susceptibility study indicated that the MERS-CoV may infect several human cell lines, including lower respiratory, kidney, intestinal, and liver cells, as well as histiocytes. ${ }^{48}$ The range of MERS-CoV tissue tropism in vitro was found to be broader than any other $\mathrm{HCoV}$.
MERS-CoV has been reported to elicit attenuated innate immune responses with delayed proinflammatory cytokine induction in in vitro and in vivo, ${ }^{49-51}$ which might lead to immune dysfunctions. Similar findings have been reported among SARS patients. ${ }^{32,52}$ The ineffective $B$ cell and $T$ cell responses with prolonged cytokine expression have also been observed among the MERS patients during advanced stages of the disease. Clinical symptoms include fever, cough, sore throat, myalgia, chest pain, and gastrointestinal symptoms, such as diarrhea, vomiting, and abdominal pain. ${ }^{5,53,54}$ Respiratory symptoms indicate the lower respiratory tract complications (dyspnea, cough, and fever); however, the upper respiratory tract complications are rare. The virus is detected in the upper 
respiratory tract only during early course of the infections, and lower respiratory tract during late stages of infections. ${ }^{21,55-57}$

In some cases, the virus is detected in urine and blood of the patients, which indicates the possibility of systemic infection. The multiple specimens should be collected from different sites at different time points to increase the possibility of detecting MERS-CoV. Priority should be given to the respiratory specimens (lower tract if obtainable and in all cases of severe disease; upper tract if the disease is mild and lower tract specimens cannot be obtained). Potential risk factors include obesity, diabetes mellitus, end-stage renal disease, cardiac disease, hypertension, lung disease including asthma and cystic fibrosis, and immunosuppressive conditions. ${ }^{24,26,53,54}$ The major complications reported in fatal cases are hyperkalemia with associated ventricular tachycardia, disseminated intravascular coagulation, pericarditis, and multiorgan failure. ${ }^{5}$ Coinfections have also been reported frequently in the cases of MERS. ${ }^{5,27,54}$ Hematological manifestations include higher leukocyte counts and lymphopenia, while a few cases showed lymphocytosis, thrombocytopenia, and coagulopathy. ${ }^{5,27}$ Elevated levels of creatinine, lactate dehydrogenase, alanine aminotransferase, and aspartate aminotransferase are indicative of renal and liver dysfunctions. ${ }^{27,58,59}$

The median incubation period for MERS-CoV (5.2 days) is slightly longer than the incubation period of SARS-CoV (4 days). MERS and SARS are respiratory viruses, but gastrointestinal manifestations have been reported among patients suffering from SARS-CoV and MERS-CoV infections. The case-fatality rate seems to be higher for MERS-CoV (around $30 \%$ ) than for SARS-CoV (9.6\%). ${ }^{60}$ The lesions and opacities in chest radiographs of the MERS patients have been reported to closely resemble the pneumonia patients infected with H1N1pdm09. ${ }^{5,59}$ The lesions in MERS patients are different from the lesions in SARS patients showing fibrocellular intraalveolar organization with a bronchiolitis obliterans organizing pneumonia (BOOP)-like pattern. ${ }^{60,61}$ MERS-CoV has been reported to induce greater dysregulation of the host response to infection than SARS-CoV. MERS-CoV has been reported to downregulate the genes involved in the antigen presentation, as an immune evasion strategy. ${ }^{62}$ The decreased expression of IFN- $\alpha$, retinoic inducible acid gene (RIG)-1, melanoma differentiation associate (MDA5), and IFN regulatory factors IRF-3 and IRF-7 have been reported in bronchoalveolar lavage (BAL) and serum of patients in advanced stages of MERS. However, the higher levels of CXC-motif chemokines ligand (CXCL) 10 and interleukin (IL)-10 have been reported among patients severely suffering from MERS, which might have resulted in the lower IFN- $\gamma$ expression and higher levels of IL-17A and IL-23. ${ }^{63}$

\section{Diagnostics and Therapeutics}

MERS-CoV seems more sensitive to prophylactic and therapeutics in vitro than SARS-CoV. ${ }^{36}$ Immunofluorescence assays have been used to detect MERS-CoV antibodies. ${ }^{64}$ IgG and IgM antibodies in serum samples could be determined using an antiMERS-CoV indirect immunofluorescence assay. ${ }^{16,65}$ In addition, the enzyme-linked immunosorbent assays (ELISA), protein microarray technology, and micro-neutralization (MN) assays have also been used to detect MERS-CoV antibodies. ${ }^{65,66}$ The real-time PCR (RT-PCR) assays targeting RNA upstream of the E gene ( $u p E$ ) and ORF-1b and ORF-1a have been also used for detection. ${ }^{32}$ According to the WHO, the screening using RT-PCR targeting upE gene should be conducted on samples from suspected MERS patients. All positive samples should undergo confirmatory testing by targeting ORF-1a, ORF-1b, or $\mathrm{N}$ genes. ${ }^{16,67}$ These RT-PCR assays have been reported to be very specific without any cross-reactivity with other respiratory viruses including hCoVs. ${ }^{32}$ Respiratory samples should be collected at least every 2 to 4 days to confirm virus clearance in the cases where two consecutive results are negative. ${ }^{32,68}$ Western blotting is also useful in the diagnosis of MERS-CoV. ${ }^{68,69}$ The samples from lower respiratory tract such as BAL and tracheal aspirates are better suited for the testing due to the higher viral loads in lower respiratory tract samples. ${ }^{70}$

Antiviral treatment under the supervision of medical experts is recommended for MERS patients with or without comorbidities, with clear symptoms of pneumonia. ${ }^{71}$ The efficacy of lopinavir/ritonavir was found to be similar to IFN- $\beta 1 \mathrm{~b}$ in experimental trials using marmosets. ${ }^{72}$ IFN- $\beta 1 \mathrm{~b}$ or lopinavir/ritonavir can be considered for treating patients, in whom the use of ribavirin is not possible due to renal dysfunction or other adverse effects. ${ }^{71}$ The combination regimen of type 1 IFN + lopinavir/ ritonavir may be considered as the first-line drug for MERS patients. ${ }^{71}$ One must monitor creatinine clearance according to renal function during the use of ribavirin. ${ }^{71}$ Antiviral treatment is generally recommended for 10 to 14 days in patients with MERS-CoV infection. ${ }^{71}$ The levels of hemoglobin, bilirubin, haptoglobin, and reticulocyte must be monitored carefully during the use of ribavirin. The use of lopinavir/ritonavir has been recommended instead of ribavirin in cases of hemolytic anemia. ${ }^{71}$ Since ribavirin is teratogenic, patients are advised not to plan for pregnancy for 6 months after treatment. ${ }^{73}$ Convalescent plasma therapy has been shown some efficacy among patients refractory to antiviral drugs if administered within 2 weeks of the onset of the disease. ${ }^{71,74}$ Convalescent plasma therapy could help some patients with severe disease. ${ }^{10,32,75}$ MERS-CoV-specific peptide fusion inhibitors have been reported as a novel approach to treat MERS patients. ${ }^{71}$

\section{Conclusion}

There is a need to understand the framework of establishment of the MERS-CoV infection in the society to develop control measures for the larger outbreaks. The involvement of pattern recognition receptors and downstream signaling at the cellular level is required to understand the molecular pathogenesis of MERS-CoV. The role of accessory proteins of MERS-CoV should be dissected out to understand their diverse roles in the immune evasion strategies adopted by MERS-CoV to inhibit IFN- $\beta$ expression. There is need to develop suitable animal models to study the MERS-CoV pathogenesis for testing antiviral drugs and vaccines. The threat of potential pandemics is always there because pathogenic CoVs continue to spill over from animals to the human population. The specific diagnostics and control measures are required to avoid the spread among healthcare workers and nosocomial infections among other patients. The 
knowledge about the dynamics and molecular characteristics of MERS-CoV and other closely related CoVs in circulation is very important to understand their emergence and to strengthen disease surveillance and disease preparedness.

\section{References}

1 Woo PC, Lau SK, Chu CM, et al. Characterization and complete genome sequence of a novel coronavirus, coronavirus HKU1, from patients with pneumonia. J Virol 2005;79(2):884-895

2 Durai P, Batool M, Shah M, Choi S. Middle East respiratory syndrome coronavirus: transmission, virology and therapeutic targeting to aid in outbreak control. Exp Mol Med 2015;47:e181

3 Weiss SR, Navas-Martin S. Coronavirus pathogenesis and the emerging pathogen severe acute respiratory syndrome coronavirus. Microbiol Mol Biol Rev 2005;69(4):635-664

4 Fouchier RA, Hartwig NG, Bestebroer TM, et al. A previously undescribed coronavirus associated with respiratory disease in humans. Proc Natl Acad Sci U S A 2004;101(16):6212-6216

5 van den Brand JM, Smits SL, Haagmans BL. Pathogenesis of Middle East respiratory syndrome coronavirus. J Pathol 2015;235(2): 175-184

6 Gaunt ER, Hardie A, Claas EC, Simmonds P, Templeton KE. Epidemiology and clinical presentations of the four human coronaviruses 229E, HKU1, NL63, and OC43 detected over 3 years using a novel multiplex real-time PCR method. J Clin Microbiol 2010; 48(8):2940-2947

7 Álvarez E, Donado-Campos J, Morilla F. New coronavirus outbreak. Lessons learned from the severe acute respiratory syndrome epidemic. Epidemiol Infect 2015;143(13):2882-2893

8 Sharif-Yakan A, Kanj SS. Emergence of MERS-CoV in the Middle East: origins, transmission, treatment, and perspectives. PLoS Pathog 2014;10(12):e1004457

9 Woo PC, Lau SK, Li KS, Tsang AK, Yuen KY. Genetic relatedness of the novel human group $C$ betacoronavirus to Tylonycteris bat coronavirus HKU4 and Pipistrellus bat coronavirus HKU5. Emerg Microbes Infect 2012;1(11):e35

10 de Groot RJ, Baker SC, Baric RS, et al. Middle East respiratory syndrome coronavirus (MERS-CoV): announcement of the Coronavirus Study Group. J Virol 2013;87(14):7790-7792

11 Woo PC, Lau SK, Li KS, et al. Molecular diversity of coronaviruses in bats. Virology 2006;351(1):180-187

12 Reusken $\mathrm{CB}$, Lina $\mathrm{PH}$, Pielaat $\mathrm{A}$, et al. Circulation of group 2 coronaviruses in a bat species common to urban areas in Western Europe. Vector Borne Zoonotic Dis 2010;10(8):785-791

13 van Boheemen S, de Graaf M, Lauber C, et al. Genomic characterization of a newly discovered coronavirus associated with acute respiratory distress syndrome in humans. MBio 2012;3(6):473-512

14 Ithete NL, Stoffberg S, Corman VM, et al. Close relative of human Middle East respiratory syndrome coronavirus in bat, South Africa. Emerg Infect Dis 2013;19(10):1697-1699

15 Haagmans BL, Al Dhahiry SH, Reusken CB, et al. Middle East respiratory syndrome coronavirus in dromedary camels: an outbreak investigation. Lancet Infect Dis 2014;14(2):140-145

16 Banik GR, Khandaker G, Rashid H. Middle East respiratory syndrome coronavirus "MERS-CoV": current knowledge gaps. Paediatr Respir Rev 2015;16(3):197-202

17 Reusken CB, Haagmans BL, Müller MA, et al. Middle East respiratory syndrome coronavirus neutralising serum antibodies in dromedary camels: a comparative serological study. Lancet Infect Dis 2013;13(10):859-866

18 Perera RA, Wang P, Gomaa MR, et al. Seroepidemiology for MERS coronavirus using microneutralisation and pseudoparticle virus neutralisation assays reveal a high prevalence of antibody in dromedary camels in Egypt, June 2013. Euro Surveill 2013;18(36):20574
19 van Doremalen N, Bushmaker T, Karesh WB, Munster VJ. Stability of Middle East respiratory syndrome coronavirus in milk. Emerg Infect Dis 2014;20(7):1263-1264

20 Alagaili AN, Briese T, Karesh WB, Daszak P, Lipkin WI. Reply to "Concerns about misinterpretation of recent scientific data implicating dromedary camels in epidemiology of Middle East respiratory syndrome (MERS)". MBio 2014;5(4):e01482-e14

21 Azhar EI, El-Kafrawy SA, Farraj SA, et al. Evidence for camel-tohuman transmission of MERS coronavirus. N Engl J Med 2014; 370(26):2499-2505

22 Vijgen L, Keyaerts E, Lemey P, et al. Evolutionary history of the closely related group 2 coronaviruses: porcine hemagglutinating encephalomyelitis virus, bovine coronavirus, and human coronavirus OC43. J Virol 2006;80(14):7270-7274

23 de Sousa R, Reusken C, Koopmans M. MERS coronavirus: data gaps for laboratory preparedness. J Clin Virol 2014;59(1):4-11

24 Assiri A, McGeer A, Perl TM, et al; KSA MERS-CoV Investigation Team. Hospital outbreak of Middle East respiratory syndrome coronavirus. N Engl J Med 2013;369(5):407-416

25 Raj VS, Osterhaus AD, Fouchier RA, Haagmans BL. MERS: emergence of a novel human coronavirus. Curr Opin Virol 2014;5:58-62

26 Arabi YM, Arifi AA, Balkhy HH, et al. Clinical course and outcomes of critically ill patients with Middle East respiratory syndrome coronavirus infection. Ann Intern Med 2014;160(6):389-397

27 Assiri A, Al-Tawfiq JA, Al-Rabeeah AA, et al. Epidemiological, demographic, and clinical characteristics of 47 cases of Middle East respiratory syndrome coronavirus disease from Saudi Arabia: a descriptive study. Lancet Infect Dis 2013;13(9):752-761

28 Zhang N, Jiang S, Du L. Current advancements and potential strategies in the development of MERS-CoV vaccines. Expert Rev Vaccines 2014;13(6):761-774

29 Tomar S, Johnston ML, St John SE, et al. Ligand-induced Dimerization of Middle East Respiratory Syndrome (MERS) Coronavirus nsp5 Protease (3CLpro): IMPLICATIONS FOR nsp5 REGULATION AND THE DEVELOPMENT OF ANTIVIRALS. J Biol Chem 2015; 290(32): 19403-19422

30 Bailey-Elkin BA, Knaap RC, Johnson GG, et al. Crystal structure of the Middle East respiratory syndrome coronavirus (MERS-CoV) papain-like protease bound to ubiquitin facilitates targeted disruption of deubiquitinating activity to demonstrate its role in innate immune suppression. J Biol Chem 2014;289(50):34667-34682

31 Perlman S, Netland J. Coronaviruses post-SARS: update on replication and pathogenesis. Nat Rev Microbiol 2009;7(6):439-450

32 Zumla A, Hui DS, Perlman S. Middle East respiratory syndrome. Lancet 2015;386(9997):995-1007

33 Smith EC, Blanc H, Surdel MC, Vignuzzi M, Denison MR. Coronaviruses lacking exoribonuclease activity are susceptible to lethal mutagenesis: evidence for proofreading and potential therapeutics. PLoS Pathog 2013;9(8):e1003565

34 Kindler E, Jónsdóttir HR, Muth D, et al. Efficient replication of the novel human betacoronavirus EMC on primary human epithelium highlights its zoonotic potential. MBio 2013;4(1):e00611-e00612

35 Zielecki F, Weber M, Eickmann M, et al. Human cell tropism and innate immune system interactions of human respiratory coronavirus EMC compared to those of severe acute respiratory syndrome coronavirus. J Virol 2013;87(9):5300-5304

36 Raj VS, Mou H, Smits SL, et al. Dipeptidyl peptidase 4 is a functional receptor for the emerging human coronavirus-EMC. Nature 2013; 495(7440):251-254

37 Li W, Moore MJ, Vasilieva N, et al. Angiotensin-converting enzyme 2 is a functional receptor for the SARS coronavirus. Nature 2003; 426(6965):450-454

38 Perlman S. The Middle East respiratory syndrome-how worried should we be? MBio 2013;4(4):531-613

39 Hocke AC, Becher A, Knepper J, et al. Emerging human middle East respiratory syndrome coronavirus causes widespread infection and alveolar damage in human lungs. Am J Respir Crit Care Med 2013;188(7):882-886 
40 de Wilde AH, Raj VS, Oudshoorn D, et al. MERS-coronavirus replication induces severe in vitro cytopathology and is strongly inhibited by cyclosporin A or interferon- $\alpha$ treatment. J Gen Virol 2013;94(Pt 8):1749-1760

41 Delmas B, Gelfi J, L'Haridon R, et al. Aminopeptidase N is a major receptor for the entero-pathogenic coronavirus TGEV. Nature 1992;357(6377):417-420

42 Raj VS, Smits SL, Provacia LB, et al. Adenosine deaminase acts as a natural antagonist for dipeptidyl peptidase 4-mediated entry of the Middle East respiratory syndrome coronavirus. J Virol 2014; 88(3):1834-1838

43 Jiang S, Lu L, Du L, Debnath AK. A predicted receptor-binding and critical neutralizing domain in $S$ protein of the novel human coronavirus HCoV-EMC. J Infect 2013;66(5):464-466

44 Imai Y, Kuba K, Ohto-Nakanishi T, Penninger JM. Angiotensinconverting enzyme 2 (ACE2) in disease pathogenesis. Circ J 2010; 74(3):405-410

45 Herlihy SE, Pilling D, Maharjan AS, Gomer RH. Dipeptidyl peptidase IV is a human and murine neutrophil chemorepellent. J Immunol 2013;190(12):6468-6477

46 Gierer S, Bertram S, Kaup F, et al. The spike protein of the emerging betacoronavirus EMC uses a novel coronavirus receptor for entry, can be activated by TMPRSS2, and is targeted by neutralizing antibodies. J Virol 2013;87(10):5502-5511

47 Lambeir AM, Durinx C, Scharpé S, De Meester I. Dipeptidylpeptidase IV from bench to bedside: an update on structural properties, functions, and clinical aspects of the enzyme DPP IV. Crit Rev Clin Lab Sci 2003;40(3):209-294

48 Cowling BJ, Park M, Fang VJ, Wu P, Leung GM, Wu JT. Preliminary epidemiological assessment of MERS-CoV outbreak in South Korea, May to June 2015. Euro Surveill 2015;20(25):7-13

49 Chan RW, Chan MC, Agnihothram S, et al. Tropism of and innate immune responses to the novel human betacoronavirus lineage $C$ virus in human ex vivo respiratory organ cultures. J Virol 2013; 87(12):6604-6614

50 Zhou J, Chu H, Li C, et al. Active replication of Middle East respiratory syndrome coronavirus and aberrant induction of inflammatory cytokines and chemokines in human macrophages: implications for pathogenesis. J Infect Dis 2014;209(9):1331-1342

51 Lau SK, Lau CC, Chan KH, et al. Delayed induction of proinflammatory cytokines and suppression of innate antiviral response by the novel Middle East respiratory syndrome coronavirus: implications for pathogenesis and treatment. J Gen Virol 2013;94(Pt 12):2679-2690

52 Cameron MJ, Ran L, Xu L, et al; Canadian SARS Research Network. Interferon-mediated immunopathological events are associated with atypical innate and adaptive immune responses in patients with severe acute respiratory syndrome. J Virol 2007;81(16):8692-8706

53 Al-Tawfiq JA, Hinedi K, Ghandour J, et al. Middle East respiratory syndrome coronavirus: a case-control study of hospitalized patients. Clin Infect Dis 2014;59(2):160-165

54 Memish ZA, Al-Tawfiq JA, Assiri A, et al. Middle East respiratory syndrome coronavirus disease in children. Pediatr Infect Dis J 2014;33(9):904-906

55 Guery B, Poissy J, el Mansouf L, et al; MERS-CoV Study Group. Clinical features and viral diagnosis of two cases of infection with Middle East Respiratory Syndrome coronavirus: a report of nosocomial transmission. Lancet 2013;381(9885):2265-2272

56 Drosten C, Seilmaier M, Corman VM, et al. Clinical features and virological analysis of a case of Middle East respiratory syndrome coronavirus infection. Lancet Infect Dis 2013;13(9):745-751

57 Memish ZA, Assiri A, Almasri M, et al. Prevalence of MERS-CoV nasal carriage and compliance with the Saudi health recommen- dations among pilgrims attending the 2013 Hajj. J Infect Dis 2014; 210(7):1067-1072

58 Al-Abdallat MM, Payne DC, Alqasrawi S, et al; Jordan MERS-CoV Investigation Team. Hospital-associated outbreak of Middle East respiratory syndrome coronavirus: a serologic, epidemiologic, and clinical description. Clin Infect Dis 2014;59(9):1225-1233

59 Ajlan AM, Ahyad RA, Jamjoom LG, Alharthy A, Madani TA. Middle East respiratory syndrome coronavirus (MERS-CoV) infection: chest CT findings. AJR Am J Roentgenol 2014;203(4):782-787

60 Nicholls JM, Poon LL, Lee KC, et al. Lung pathology of fatal severe acute respiratory syndrome. Lancet 2003;361(9371):1773-1778

61 Tse GM, To KF, Chan PK, et al. Pulmonary pathological features in coronavirus associated severe acute respiratory syndrome (SARS). J Clin Pathol 2004;57(3):260-265

62 Josset L, Menachery VD, Gralinski LE, et al. Cell host response to infection with novel human coronavirus EMC predicts potential antivirals and important differences with SARS coronavirus. MBio 2013;4(3):e00165-e13

63 Faure E, Poissy J, Goffard A, et al. Distinct immune response in two MERS-CoV-infected patients: can we go from bench to bedside? PLoS ONE 2014;9(2):e88716

64 Meyer B, Drosten C, Müller MA. Serological assays for emerging coronaviruses: challenges and pitfalls. Virus Res 2014;194:175-183

65 Spanakis N, Tsiodras S, Haagmans BL, et al. Virological and serological analysis of a recent Middle East respiratory syndrome coronavirus infection case on a triple combination antiviral regimen. Int J Antimicrob Agents 2014;44(6):528-532

66 Gossner C, Danielson N, Gervelmeyer A, et al. Human-dromedary camel interactions and the risk of acquiring zoonotic Middle East respiratory syndrome coronavirus infection. Zoonoses Public Health 2016;63(1):1-9

67 Shirato K, Yano T, Senba S, et al. Detection of Middle East respiratory syndrome coronavirus using reverse transcription loop-mediated isothermal amplification (RT-LAMP). Virol J 2014;11:139

$68 \mathrm{Du} \mathrm{L}$, Zhao G, Kou Z, et al. Identification of a receptor-binding domain in the $S$ protein of the novel human coronavirus Middle East respiratory syndrome coronavirus as an essential target for vaccine development. J Virol 2013;87(17):9939-9942

69 Raj VS, Lamers MM, Smits SL, et al. Identification of protein receptors for coronaviruses by mass spectrometry. Methods Mol Biol 2015;1282:165-182

70 Memish ZA, Al-Tawfiq JA, Makhdoom HQ et al. Respiratory tract samples, viral load, and genome fraction yield in patients with Middle East respiratory syndrome. J Infect Dis 2014;210(10): 1590-1594

71 Chong YP, Song JY, Seo YB, Choi JP, Shin HS; Rapid Response Team. Antiviral treatment guidelines for Middle East respiratory syndrome. Infect Chemother 2015;47(3):212-222

72 Chan JF, Yao Y, Yeung ML, et al. Treatment with lopinavir/ritonavir or interferon- $\beta 1 \mathrm{~b}$ improves outcome of MERS-CoV infection in a nonhuman primate model of common marmoset. J Infect Dis 2015;212(12):1904-1913

73 Gara N, Ghany MG. What the infectious disease physician needs to know about pegylated interferon and ribavirin. Clin Infect Dis 2013;56(11):1629-1636

74 Mair-Jenkins J, Saavedra-Campos M, Baillie JK, et al; Convalescent Plasma Study Group. The effectiveness of convalescent plasma and hyperimmune immunoglobulin for the treatment of severe acute respiratory infections of viral etiology: a systematic review and exploratory meta-analysis. J Infect Dis 2015;211(1):80-90

75 Hui DS, Memish ZA, Zumla A. Severe acute respiratory syndrome vs. the Middle East respiratory syndrome. Curr Opin Pulm Med 2014;20(3):233-241 